\title{
Scientia sexualis and ars erotica: Indonesian young people resisting the discourse of sexual desire
}

\section{Teguh Wijaya Mulya}

To cite this article: Teguh Wijaya Mulya (2020): Scientia sexualis and ars erotica: Indonesian young people resisting the discourse of sexual desire, Psychology \& Sexuality, DOI:

10.1080/19419899.2020.1751250

To link to this article: https://doi.org/10.1080/19419899.2020.1751250

Accepted author version posted online: 02

Apr 2020.

Published online: 14 Apr 2020.

Submit your article to this journal $\widetilde{ }$

Q View related articles $\sqsubset$

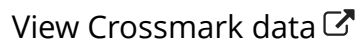




\title{
Scientia sexualis and ars erotica: Indonesian young people resisting the discourse of sexual desire
}

\author{
Teguh Wijaya Mulya (D) \\ Faculty of Psychology, University of Surabaya, Surabaya Indonesia
}

\begin{abstract}
Based on a qualitative study conducted with Indonesian young people, this article explores the ways in which the discourse of sexual desire - that constitutes sexual self as categorisable into LGBT+ identities - may be contested in the participants' sexual becoming. Employing Michel Foucault's comparison of scientia sexualis (science of sex) and ars erotica (erotic art), participants' narratives are analysed to explore new possibilities of sexual subjectivity without both categorising into or rejecting LGBT+ subject positions. The findings show that participants have taken up a subject position offered by the discourse of sexual desire, but they simultaneously resisted its scientia sexualis mechanisms by positioning the art of sexual pleasure, rather than specification of desires, at the centre of their becoming sexual subjects.
\end{abstract}

ARTICLE HISTORY

Received 7 August 2019

Accepted 30 March 2020

\section{KEYWORDS}

Sexual desire; sexual subjectivity; young people; Indonesia

\section{Introduction}

This article engages with the ways the discourse of sexual desire has been drawn on and contested in the constitution of Indonesian young people's sexual subjectivity. The discourse of sexual desire refers to a set of interconnected ideas that constitute sexual attraction and practices as categoriseable, nameable, specifiable, and relatively unchanging (Davidson, 2001; Foucault, 1997). This discourse offers a range of subject positions or sexual 'identities,' such as gay, lesbian, bisexual, and heterosexual, by which individuals may give meaning and legitimacy to their sexual selves. Acknowledging that the discourse of sexual desire has been both enabling and limiting, this article aims to extend the knowledge around this discourse by examining three vignettes of Indonesian young people's sexual subjectivity using Foucault's comparison of scientia sexualis (the science of sex) and ars erotica (erotic art). Specifically, it argues that some young Indonesian participants in this study have taken up subject positions offered by the discourse of sexual desire, but their narratives also resist the discourse's scientia sexualis disciplinary mechanisms. Their resistance is conducted not by completely rejecting identity categories, but - by cultivating new ways of being sexual subjects that resemble Foucault's (1978) ars erotica. This means that these participants' ways of becoming sexual subjects indicate less emphasis on truth, fact, method, verifiability, classification, and specification; and more on creativity, beauty, pleasure, relationship, and new possibilities.

\section{Scientia sexualis, ars erotica, and the limitations of the discourse of sexual desire}

The discourse of sexual desire has enabled certain ways of being sexual subjects, that is, through the specification and categorisation of sexual desires. This means of constituting sexual subjectivity has 
been crucial for providing social and legal recognition of LGBT+ sexualities in various countries in the last four decades (Foucault, 1997; O'Flaherty \& Fisher, 2008). However, this constitution of sexual subjectivity through the discourse of sexual desire also entails some limitations. The first limitation to the categorisation of sexual orientation wrought by the discourse of sexual desire is that it implies relatively fixed and stable sexual categorisation or 'identities.' While this has enabled sexual desires to be named, recognised, and validated, this fixity also constrains the possibility that sexual subjectivity might be multiple, fractured, and always in the process of becoming (Weedon, 1987). In support of this critique, some empirical studies have evidenced that sexual orientation categories might be fundamentally unstable and fluid (e.g., Better \& Simula, 2015; Diamond, 2008). Overlapping with this critique, the second limitation arises from the fact that the categorisation of sexual desires necessitates definitions and specifications, resulting in the exclusion of those who do not 'fit' such a specification. Promoting polyamory as a sexual orientation (Tweedy, 2011), for instance, requires the construction of 'criteria' that define what polyamorous desire entails. Klesse (2014) noted that contemporary studies around polyamory as a sexual orientation tended to prioritise loving relationships and long-term commitment, excluding other possibilities of multi-partner arrangements which can differ greatly in terms of closeness, emotionality, and commitment.

These limitations have been addressed by previous scholars who have explored other possibilities of the constitution of sexual desire. Some scholars have proposed a complete rejection of any sexual categorisations, embracing instead the radical instabilities and potentialities of sexual desire (Carastathis, 2008; Gamson, 1995; Nash, 2013). However, Foucault (1997) did not support such a total dismissal of the categorisation of sexual orientation. Rather, he acknowledged the importance of social movements based on fixed and stable sexual identities constituted through the discourse of sexual desire. He noted that identity-based movements which focused on sexual rights are 'important,' 'must be supported,' and have brought about a 'real liberation process,' as in some Western countries in the early seventies (p. 164). However, he also asserted that 'we have to go a step further,' that is, to 'escape as much as possible from the type of relations that society proposes for us' (p. 160) and create new forms of life, relationships, and friendships beyond those sexual categorisations. Foucault calls for a cultural endeavour 'that invents ways of relation, types of existence, types of values, types of exchanges between individuals which are really new' (pp. 159-160). Responding to this call, this article will seek alternative ways of extending knowledge on sexual desires without rejecting categories of sexual orientation. To this end, I will employ Foucault's (1978) concepts of scientia sexualis and ars erotica to explore such alternatives in Indonesian young people's ways of being sexual subjects.

Foucault (1978) has identified the concept of sexual desire as part of a wider political project of making sexuality an object of science, or scientia sexualis. Through scientific analyses, classification, and theorisation of sexual desire, power administrates, regulates, (de)pathologises, and exercises disciplinary control over sexuality. Envisaging sexuality beyond such discursive regulation, Foucault offered the notion of ars erotica to think differently about sexuality - where the focus is less on the legal, scientific, or social 'truth' about sex, and more on the creative pursuit of sexual pleasure, particularly how to maximise its intensity, quality, and duration. In the current study, some participants have drawn on and contested dominant meanings circulated via the discourse of sexual desire in ways that resemble Foucault's ars erotica. The constitution of their sexual subjectivities did not always involve mechanisms of naming, specification, classification, and (de)pathologisation of sexual desire, nor was it necessarily engaged in pursuing a scientific 'truth' about their desire. Rather, it involved artistic engagement, imagination, creativity, fictionalisation, and embodiment of alternative sexual pleasures.

\section{Methodological notes}

The data for this article came from a study involving 22 Indonesian youth aged 16-24 on Indonesian youth's sexual subjectivities (Wijaya Mulya, 2017). Twelve participants identified as male, nine as female, and one as neither gender. Fourteen identified as heterosexual, 4 gay, 2 lesbian, 1 bisexual, 
and 1 asexual. At the time of the interview, participants were college students (8 participants), high school students (6 participants), employees (5 participants), a freelance journalist (1 participant), a postgraduate student (1 participant), and an NGO activist (1 participant). After ethics permission was obtained, participants were recruited through an advertisement distributed to NGOs, universities, and communities in several cities in Indonesia. To maintain confidentiality, the name of these cities and organisations is not disclosed and all names used in this article are pseudonyms. Participants made first contact through email and were sent an information sheet, consent form, and given the opportunity to ask questions before signing electronically. Among 24 youth who made contact, one refused to participate after reading the information sheet because she felt she was unsuitable for the study, and one withdrew in the middle of the email interview because he was too busy with his study.

The data construction took place between April and October 2013. First, each consenting participant engaged in email interviews (semi-structured) with the researcher (10-20 correspondences per participant), then a 1-hr session of instant messenger chat was conducted with the purpose of clarifying or deepening some topics discussed in the email interviews. Finally, participants emailed an autobiographical writing about themselves relevant with the topic studied. The questions were around their sexual knowledge, identity, self-understanding, and experiences. The interviews were conducted in Bahasa Indonesia and translated into English by the researcher for this article. As a native Indonesian speaker, the researcher found few difficulties during the translation. Almost all of participants' words have a comparable term in English; and when it has not, it was left in Bahasa and explained in a bracket. A colleague who is a native Indonesian speaker and has a doctorate from an English-speaking country checked the translation accuracy before the article was submitted to this journal.

The data were analysed using thematic analysis steps suggested by Braun and Clarke (2006). Firstly, the researcher familiarised himself with the data, organised them, and then he searched, specified, and reviewed key themes found in the data. In line with the purpose of the study and its Foucauldian poststructuralist underpinning, the themes generated were focused on dominant discourses drawn upon by participants in understanding sexuality, and their alternative subjectivities which may possibly challenge those discourses (Weedon, 1987; Willig, 2013). Following this analytical orientation, comprehensively representing participants or the data were not as methodologically important as exploring new discursive possibilities. Therefore, this article does not attempt to provide an all-encompassing, extensive depiction of participants' narrative. Instead, participants' narratives in this article were selectively chosen to best illustrate Indonesian youth's engagement with the discourse of sexual desire and, more importantly, possibilities to contest it. Three participants - Bianda, Heni, and Putri (pseudonyms) - were chosen because of their specific engagement with this discourse in the constitution of their sexual subjectivitiy. Other dominant discourses identified within the data (e.g., from the other 19 participants) were examined in separate publications (Wijaya Mulya, 2018a; 2018b; 2019).

Throughout the data construction and analysis, the researcher continuously reflected on his own positionality, both personally, theoretically, and methodologically. For instance, being mindful of his traditionally-powerful position as a male adult researcher who is cisgender and heterosexual, he gently and frequently reminded participants that they do not need to feel hesitate to refuse answering questions if they feel uncomfortable. Another example is his methodological commitment to be as collaborative as possible with the participants in co-constructing the data, which resulted in an openness to listen to participants' story outside of the interview guide (e.g., their hobby, their self-harm) as long as it is not too irrelevant.

During the analysis, an ethical concern over interpretive authority (in this case, relabelling participants' sexual identity using terms they did not use) has emerged and thought upon reflexively. Seeking to respect participants' agency, the researcher decided to listen to their self-understanding and did not attempt to 'correct' them. Instead, the analysis sought to criticise a macro-level set of assumptions (i.e., discourse) given rise to the preoccupation with the naming of one's desire, that is, scientia sexualis; and offer an alternative reading of the data through ars erotica lens which are, hopefully, more ethical, egalitarian, and insightful. 


\section{Findings}

Three narratives exhibiting the art of cultivating alternative subjectivity in relation to the discourse of sexual desire will be presented in this section. The analysis here is not intended to be comprehensive, exemplary, nor exhaustive; rather, it is intended to be disruptive or provocative. It seeks to encourage creative explorations of new understandings, sexual practice, relationship, and pleasure - or the art of being sexual subjects - without specifying new sexual identifications and without completely rejecting the existing LGBT+ category either.

\section{Bianda's story: to name or not to name one's desire?}

Bianda (24, office worker, female, bisexual) had just completed her university degree and was working as an office worker when I interviewed her. She identified herself as bisexual, a term she learned from her friends at university. Here, Bianda drew on the discourse of sexual desire in the constitution of her subjectivity and took up the bisexual subject position offered. More than just bisexual, her journey of becoming a sexual subject also demonstrated a constant tendency of engaging in simultaneous multiple relationships since the first time she was involved in an intimate relationship. She did not label this constant tendency using a fixed sexual identification, such as 'polyamorous.' I argue that her refusal to categorise her sexuality under a certain identity might open up a new, alternative, way to (dis)engage with/from the discourse of sexual desire, that is, through the art of developing various forms of relationship.

I didn't know about homosexuality until I went to uni. I have some friends who called themselves lesbian there. I've been dating girls before but I thought it's just a joke, just for fun. I don't think I'm a lesbian, because I like boys too. I think I'm a bi. It's not my choice. It is my fate which God has decided.

When I was in intermediate school ( \pm 12-15 years old), my friends already called me a playgirl because I changed boyfriends many times. It's my bad habit. I'm easily bored with things, and lovers too! I started dating girls when I was 16. I dated both boys and girls. Even when I was in a relationship with a boy, I still can get close to girls. They didn't know, of course. I thought girls and boys are different, so no need for jealousy. But now I know it's wrong. They both have feelings.

My first girlfriend was, let's call her, J. She said she likes me, and I like her too. So we were together for 2.5 years. Then I broke up with her because I like another guy, and he asked me to leave my girlfriend. But I was only with him for 1.5 years. After that I came back with J, and for the first time I fell in love with her. When I was close with J, I was introduced to her friend, L, who also seems like a butch. $L$ was interested in me too. I actually didn't want to be with $L$, because I loved J. But $L$ told me stories about $J$ that hurt my feelings. Eventually I dated $L$, and I felt comfortable with her. While I was in a relationship with $L$, there was another butch said she likes me, let's called her U. But I didn't want to be with her. So we just became good friends, L, U, and me. After I broke up with L, I returned to my ex-boyfriend and we were together again. Then we broke up and I got close with N, another butch. But it's a relationship without status, because I didn't want any commitment. After one year, we split. Then I got close to another butch, let's called her B. We were together for 1.5 years, until I met a guy who looks like my ex-boyfriend and I dated him. But it was not long, just around one year. Then I returned to B. I was with B until I met another guy, his name is $\mathrm{E}$. After I broke up with $\mathrm{E}$ I haven't had any relationships. I am just close to my exgirlfriend, B, but she already has someone else now, so I can't get too close to her.

I'm now officially single. I am now close with a new guy, but it's a relationship without status. I like this 'relationship without status' thing. Haha. He knows in the past I had relationships with girls. But he doesn't know that I am now also close to my butch, B; whereas B knows I am with this guy.

I know my relationship with a girl will never end up in marriage. So my dream is to marry a guy. But I don't know ... very likely, although I am married, I will still be interested to have a relationship with girls. Haha! And I will never let him know. That's impossible! I definitely will keep it secret. He will be very disappointed if he knows. No husband will let me have relationships with girls. Although, it would be awesome if that kind of guy exists! (Email interview)

A reading of Bianda's narrative through the discourse of sexual desire may identify Bianda as a bisexual woman who is also polyamorous. Polyamory refers to the engagement in consensual 
simultaneous multiple relationships which may be both emotional and/or sexual in nature (Barker \& Langdridge, 2010). Scholars have suggested that polyamory be included in sexual orientation categories; these scholars argue that polyamory is a relatively fixed state and deeply embedded in one's sense of self (Tweedy, 2011). As her narrative has repetitively shown, Bianda has developed many relatively stable intimate relationships with women and men, ranging in length from 1 to 2.5 years. Even at an early age, she was called a 'playgirl' because she tended to change boyfriends frequently. More than being bisexual, Bianda showed a constant tendency to develop multiple relationships. She did not just develop a new relationship with a girl when she had a boyfriend or vice versa (because of her bisexuality), but also had new relationships with other girls when she already had a girlfriend. Through the discourse of sexual desire, Bianda can be seen as occupying a polyamorous subject position in addition to her bisexuality.

There are two concerns in this way of reading through the discourse of sexual desire. Firstly, while a polyamorous subject position might enable Bianda to view her inability to stay with one lover as an orientation rather than a problem, naming and specifying Bianda's desire as polyamorous also risks the confinement of her sexual potentialities into an identification with limited meanings attached to it. The dominant meanings around polyamory which prioritise loving and long-term commitment (Klesse, 2014), for example, might limit Bianda's possibilities in understanding and practising sexuality. Secondly, since she did not refer to this term herself, there is an ethical concern over interpretive authority in reading Bianda as polyamorous. I imposed an interpretation or label which she might not agree to be read as such, and thus, might not feel respected. Such re-labelling or 'correction' is against the theoretical framework, methodology, and the purpose of this study.

Escaping this tension of naming and not naming Bianda's sexual desire, here I will attempt to relinquish this analytical desire of scientia sexualis (identifying, naming, specifying) by exploring alternative ways Bianda's narrative might resist the discourse of sexual desire without focusing on the classification of her desire. To this end, I will trace various changes, themes, tones, or rhythms along this journey - that is, the journey of understanding her sexual desire, her sexual selves, or her art of being a sexual subject.

While Bianda has taken up the bisexual subject position offered by the discourse of sexual desire, in her narrative she did not talk much about this identity, such as its nature, characteristics, or specifications. She talked about it in the beginning, as to how it was not her choice or how she came to understand herself as bisexual, but the larger theme in her narrative is her relationships, not her desire. Her narrative exhibits a rich variety of ways in engaging in intimate relationships from the bisexual position she occupied. In the beginning, she had multiple simultaneous relationships which she kept secret from each of her partners. After she realised that it hurt her girlfriends'/boyfriends' feelings, she tried monogamous relationships. Most of these attempts resulted in break-ups, particularly because there was a third person. However, a return to an ex after breaking up was not uncommon in her narrative. Near the end of her story, Bianda's rhythms of relationships slowed down slightly. She explored alternatives to the expectation of fidelity in a traditional monogamous relationship using the notion of 'relationship without status' (more discussion below). She described it as 'I am close with' instead of proclaiming boyfriend/girlfriend status. As to her future aspiration, Bianda mentioned a (monogamous) heterosexual marriage, although she was not sure she would or could deny her longing for relationships with women. Here, there are at least four different kinds of relationship Bianda had engaged in or aspires to have multiple simultaneous relationships, serial monogamous relationships, 'relationships without status,' and marriage.

Instead of reading Bianda's story through the discourse of sexual desire (where she is seen as a bisexual who is also polyamorous), an alternative reading resisting this discourse might view Bianda as a bisexual with creativity in developing various kinds of relationship. Put another way, Bianda's narrative demonstrates that sexual practices and relationships might not always be neatly contained in a category of sexual orientation. Sexual categories, orientations, or identities might be specified and taken up, but this does not necessarily exclude the possibility of the proliferation of different forms of life, love, relationships, and ways of being which are driven by this energy called sex. 
While most of Bianda's forms of relationship are not genuinely 'new,' one example that is quite new is the notion of 'relationship without status' which she has drawn on near the end of her story in giving meanings to her relationship. The notion of 'relationship without status' has been quite popular among contemporary Indonesian young people (Smith-Hefner, 2007). Known by the abbreviation HTS (hubungan tanpa status = relationship without status), it refers to a situation when two Indonesian young people get intimately close, but they do not make any commitment nor declare any boyfriend/girlfriend status. Using this arrangement Bianda has escaped the expectation of fidelity in the traditional monogamous dating relationship. Bianda has showed that, in her becoming a sexual subject, she does not need to name her desire (i.e., polyamorous) and confine her sexuality to an orientation. Rather, she explored new possibilities by naming the relationship, not the desire. This analysis of Bianda's narrative contributes to the tension between naming and not naming one's sexual desire, that is, by focusing on the problematic, productive, and intertwined exchanges between sexual desire and sexual relationship; in order to explore a possibility of new forms of relationship and love.

\section{Heni's story: real desire, real pleasure, real sex?}

Heni (24, postgraduate student, female) identifies herself as asexual. She considers herself as never having had any sexual interests or attractions to either men or women. In this subsection I argue that, while Heni has been enabled by the discourse of sexual desire to identify herself as asexual, she has also resisted its scientia sexualis underpinning by exhibiting the art of exploring new sexual possibilities and enjoyment without necessarily categorising, naming, and specifying them. This analysis of Heni's narrative seeks to complicate the boundaries between sexual and non-sexual pleasure, reality and fiction, beauty and pathology, and thereby extends/questions the meaning of being a/ sexual.

I've never dated anyone. Well, I had a crush on boys ... (but) I don't want to have a relationship with him, or have sex with him. Not even in my fantasy ... it's clear that I've never wanted to have sex ... I was a bit confused (about) why they (her friends) talked about sex as if it is something really WOW, as if it is really an important thing, and it must be there. For me, sex is not everything. Sex is not in my brain.

I actually don't really care, I am what I am. But my friends in the NGO keep asking me, 'what are you?' Until one day I read a post about asexuality in an LGBTIQ Facebook page, and I felt like 'aha'. So I think I'm asexual. (Email interview)

In this narrative, Heni understands herself using a sexual identification constituted through the discourse of sexual desire, namely, an asexual person. Before, Heni actually did not care to label her sexuality. She simply thought that 'I am what I am.' However, it was not intelligible for her friends in an LGBT+ NGO, who 'keep asking' about her sexual desire. Heni managed to find a label to identify herself with: asexuality. As previous studies have documented, there have been efforts to include asexuality in the categories of sexual orientation in addition to the more established LGBT categories (Bogaert, 2006). By taking up this asexual subject position, Heni was able to explain her sexual subjectivity through the discourse of sexual desire - a discourse that appeared to be dominant among her friends in her LGBT+ NGO.

However, in examining closely Heni's narrative in relation to the traditional understanding of asexuality, it is difficult to ignore how sexuality has played an important role in her sense of self. Her work, her study, and her hobby are all related to sexuality. She studied transgendered people's sexuality for her master's thesis. She has been intensively involved as an activist in an LGBT+ NGO for several years. One of the topics during the interviews in which Heni showed great passion and excitement in talking about was her interest in yaoi (Japanese gay-themed comics). I will discuss this interest further, as it might have opened up a new possibility of disrupting the discourse of sexual desire. 
Yaoi refers to a fan culture that rereads and reconstructs male heterosexist society along the lines of female desire, particularly in the form of fictional materials around gay relationships (Kotani, 1994). Yaoi is a part of the Japan-originated otaku culture, that is, groups of fans who have strong affinity with fictional characters, possess the object they love through fictionalisation, or make the fiction itself their sexual object (Tamaki, 2007). Below is Heni's narrative on her engagement with yaoi:

\begin{abstract}
When I was at Year 4 ( $\pm 9-10$ years old), a friend gave me a yaoi because she said it's very cute. It's a kind of comic that was made by a fan, based on the characters in other famous comics/movies. So the writer can pair any characters they like. Starting from this kind of comic, I then explored other things like original gay comics, gay cartoons, and gay movies. I learned a lot about sexuality from these comics. If I'm not too busy, I usually read at least one fan fiction entry every day.
\end{abstract}

In Indonesia, there are many yaoi fan clubs. We have our own online forums based on our favourite characters and pairings. Perhaps people will see me and my friends as freaks or mad, because we believe, hope, and want these characters and pairings to be real. Quite often we have online wars (via Twitter, and Tumblr) because we don't like our favourite character being paired with another character by another fan club. If you have been in this yaoi world for a while, you'll be able to differentiate which fans really believe the pairings, and which ones are just following popular trends. If you're just following the trend, you will think that these pairings are just cute 'bromance' fantasy in fan fictions. You'll never think these gay lovers can be real.

When reading yaoi, for me the erotic scene was not the sex, but the moment before sex, when they kiss; and after sex, after ejaculation, when they hug each other. These are my favourite moments.

Eventually I decided to come out to my mom that I like yaoi and so on. My mom was not surprised. She is okay and stayed cool. (Email interview)

Heni's relationship with these erotic materials is more than just a hobby, rather, it has become an inseparable part of her sense of self. She has devoted her time every day to read yaoi. She joined a yaoi community. More than just a temporary interest, Heni's relationship with yaoi has lasted for more than 14 years. She differentiates herself as one who is a 'real believer' of this fictional reality from those who are just 'following popular trends.' She articulates her relationship with yaoi using the same language as an LGBT+ person might by using the term 'come out' when she told her mother about it. These narratives show that Heni has developed a long-term, profound, and intimate emotional (and, in a way, sexual) relationship with these materials. Such a relationship fits the criteria of sexual orientation, if the object is a human being. Reading her narrative through the discourse of sexual desire, it can be argued that Heni might not be completely asexual. Instead, she might have a kind of sexual desire which is yet to be named.

Again, there are at least two problems with a reading of Heni's narrative through the discourse of sexual desire. The first is a concern over interpretive authority. Heni herself does not consider her passion and relationship with these fictional materials as her sexual orientation. Naming her desire as something else in this analysis, to a degree, overrides her way of understanding herself - this would be against my commitment to not simply relabel nor correct participants' self-understanding. Secondly, such 'desire' for sexual enjoyment through fictional materials (otaku sexuality) is often considered as not a 'real' sexual desire or pleasure, as it is 'supposed' to be enjoyed by mature adults in 'real' sexual relationships, but merely an 'imaginative' pleasure (Kotani, 1994; Tamaki, 2007) fictional, immature, and even pathological. Whether it is authentic/real or pathological/unreal, naming this fictionalised sexual enjoyment as a desire entails both an enabling and a limiting of possibilities. While this specification enables a way of giving meaning to one's sexual subjectivity, it also simultaneously pins down radical potentialities of (otaku) sexuality into those specifications.

One alternative possibility for reading Heni's narrative - which may transcend individual-level analysis and more into macro-level discursive contestations - is by focusing on the ars erotica of enjoying pleasure instead of the scientia sexualis of categorising desire. For, according to Foucault, pleasure has the capacity 'to detach the individual from the stable, coherent identity through which modern sexuality is administered and regulated' (Jagose, 2010, p. 523). In analysing Heni's narrative, this means exploring new possibilities of sexual pleasure instead of new possibilities of sexual 
orientation. In her narratives, Heni actually did not really worry about naming or labelling her desire, except to satisfy her friends who had nagged her continuously. The larger part of her narrative exhibits more of her excitement, passion, and pleasure in engaging with yaoi materials, including its community, online wars, 'unreal' hope, and 'madness' or 'freak-ness'. Heni has invested her time and energy for more than half of her life in the world of yaoi, not because it is who she is, but because she enjoys it. She reads at least one yaoi fan fiction every day because it gives her pleasure. Her involvement in the yaoi online community and wars has brought passion and excitement into her life. In her autobiographical writing, Heni included yaoi as one of the projections of her self which she described as a friend whose house is very interesting and comforting: 'In their house you will feel a great happiness and comfort. You know why? Because they seem to really enjoy everything they do.' These narratives show that pleasure and enjoyment, not any specification of desire, have been a central theme in Heni's engagement with yaoi.

Heni's engagement with yaoi resisted the discourse of sexual desire - not by rejecting the whole idea of sexual categorisation, but - by bringing into question the very meaning of sexual interest, attraction, pleasure, and desire. Can we think of Heni as completely not having sexual interest? If not, can we think of Heni as having a kind of sexual interest or attraction (which makes her no longer asexual)? What should we call her sexual orientation then? Is her pleasure in reading yaoi completely non-sexual? If not, is it a 'real' sexual pleasure? Can her way of being sexual be seen as creative and artistic, an example of aesthetic of existence? Or is it just immature and pathological? These unanswerable questions substantiate Foucault's assertion that 'no one knows what pleasure is' (Foucault, 1997, p. 268). Rather than problematising Heni's self-understanding, this section has demonstrated how Heni's narrative has complicated meanings circulated through the discourse of sexual desire which categorises humans into groups of sexual orientation, by indicating the im/ possibility of categorising sexual desire as such.

\section{Putri's story: an erotic art of pleasure/pain?}

Putri (22, college student, lesbian) was in the last year at university and doing a bachelor thesis when I interviewed them. Through the discourse of sexual desire Putri has identified themself as a lesbian, and in term of gender, neither man, woman, nor transgender (therefore, addressed here as they). One of the main themes during the interviews is the engagement in what Putri called self-cutting or self-injury, in which Putri secretly cut their skin with a razor blade when they were in a difficult emotional condition. Analysis of Putri's narrative here invokes Foucault's (1997) call to cultivate the art of exploring bodily pleasure (which Putri showed through their self-cutting practice), as opposed to the science of specifying, categorising, and (de)pathologising sexual desires.

Now I start accepting myself as a lesbian. But sometimes, when there were triggers, like difficult circumstances, my hatred toward myself came again. I tried to destroy myself. But I am grateful it is not as bad as it was.

One day, I was feeling down. I didn't want to do anything. Just stayed in my room. Doing nothing. I have no desire to live. Then I was thinking of taking my own life. It's better for me to die rather than bring shame to people around me. But suddenly my whole life flashed in front of me, from my childhood to that day. I saw God has always been there, lending me a helping hand. Since then, I promised to never give up, to keep bouncing back, whatever the problem I had.

Now it's only self-injury that I find really difficult to let go. I still can't stop cutting. It actually helps me. When I see blood come up, I feel relieved. I am satisfied when I feel pain and blood comes up from my body. If not, I won't be satisfied. Sometimes I still do it secretly. Not very often, depending whether I can hold it or not. Like recently, it was quite frequent, once a week or fortnight. I just keep trying to not do that again. (Email interview)

Drawing on the discourse of sexual desire has enabled the constitution of Putri's sexual attraction to women as an orientation, and Putri has learned to 'accept' this lesbian identity as a part of their identity. While Putri's understanding of their desire is based on this scientia sexualis specifications and categorisations, their narrative also shows an alternative potential of the body to produce pleasure 
beyond those categorisations of desire. Specifically, I argue that there might be a possibility to see Putri's engagement with self-cutting as a kind of sexual pleasure, and that this pleasure might be enjoyed ethically - without necessarily being specified as a new sexual orientation.

Previous scholars have identified the relationship between self-cutting (like Putri has practised) and sexuality, through psychoanalysis. Almost always taking place after puberty, self-cutting has been documented as relating to childhood sexual abuse, but with very little awareness of its sexual 'nature' or underpinning (Suyemoto, 1998). These findings correspond to Putri who started practising selfcutting after puberty, did not link their sexuality and their self-cutting, and had experiences of child sexual abuse. Self-cutting has been analysed as an attempt to self-destroy or self-punish the body, which is viewed as deserving punishment (Klonsky, 2007). Likewise, Putri describes the cutting as a part of their larger desire to 'destroy themself' because Putri does not want to 'bring shame' to the people around them. By taking control of penetration and pain, self-cutting functions as a defence against an unpleasant sexual complex by turning passive into active engagements. The sadomasochistic character of self-cutting also accommodates the need to be in control of the painful/pleasurable relationship with the body (Gardner, 2013). Correspondingly, it is this pleasure of pain in an active and fully controlled situation that Putri seeks in self-cutting: 'When I see blood came up, I feel relieved. When I feel pain, I am satisfied.' These studies have demonstrated that there is a possibility of giving meaning to Putri's self-cutting as a sexual engagement, or at least containing some kinds of sexual texture.

However, such reading of Putri's narrative has again raised an ethical concern of interpretive authority. Putri themself does not give any sexual meaning to the self-cutting. While psychoanalytic scholars above have argued that sexual issues give rise to self-cutting subconsciously, this gesture risks an overriding of Putri's own way of articulating their (sexual) self, and possibly, a denial of Putri's agency as a sexual subject - a move I am committedly against. Alternatively, Foucault's (Foucault, 1997 , p. 165) invitation to explore bodily pleasures without necessarily linking them to the notion of sexual pleasure might offer a new insight for this situation.

Foucault: The idea that bodily pleasure should always come from sexual pleasure as the root of all our possible pleasure - I think that's something quite wrong. These practices are insisting that we can produce pleasure with very odd things, very strange parts of our bodies, in very unusual situations, and so on.

Interviewer: So the conflation of pleasure and sex is being broken down.

Foucault: That's it precisely. The possibility of using our bodies as a possible source of very numerous pleasures is something that is very important.

Following Foucault's remark above, one way to analyse Putri's narrative is by focusing on the exploration of new possibilities of pleasure rather than new categorisations of desire; in other words, drawing on the notion of ars erotica to discursively contest scientia sexualis in reading the data. Here, there is no urgency to ask questions such as whether Putri's pleasure is sexual or not, normal or pathological. Instead, relevant questions will be how to maximise, to intensify, and to ethically engage in these pleasurable acts. As long as they are pleasurable and ethical, it does not matter whether or not they are sexual/non-sexual/normal/pathological/cannot be dichotomised that way. It does not matter that they involve very odd things, very strange parts of our bodies, or very unusual situations. By focusing on Foucault's notion of pleasure instead of desire, the analysis of Putri's subjectivity might escape from the discourse of pathology and abnormality commonly associated with the concept of desire within scientia sexualis. For, as Foucault identified, 'desire holds a grip on the subject which is central to the constitution of a science of sexuality' (Davidson, 2001 , p. 213). In contrast, pleasure is only related to itself, it is free of use and almost devoid of meaning. There is no 'abnormal' or 'pathology' of pleasure (Davidson, 2001).

Therefore, my discussion here will now shift to the question of ethics: Can self-cutting as an alternative source of bodily pleasure be practised ethically, that is, in term of caring of the self? 
Although these are very limited, some studies have examined the possibility of self-injury as a pleasurable and ethical practice. For instance, Chandler (2012) and Inckle's (2011) studies have demonstrated how self-injury can, and should be, seen as a legitimate and beneficial coping strategy because it provides relief and temporary means of emotional survival. While self-injury has been commonly misunderstood as attempted suicide, these studies showed that self-injury functions as a survival mechanism (Suyemoto, 1998), which is the opposite of a suicidal act. These researchers argued that a preventive or 'abstinence' approach which attempts to eradicate a person's self-injury behaviours completely has been ineffective and even intensified the person's distress. Alternatively, they suggested a harm minimisation approach which views that self-injury may be necessary to provide pleasurable relief at a given point. This approach focuses on supporting the person's selfinjury so that the risk and damage can be minimal but the pleasure is optimal. In this way, self-injury is constituted as an ethical and pleasurable choice one can practise with one's own body, as long as the harm is carefully managed.

Practically, Inckle (2011) has suggested at least three components of a harm-minimisation approach which her participants have demonstrated as beneficial. The first is better support in understanding the risks inherent in different types of self-injury. For self-cutting, it is the attention to nerve, tendon, ligament, and artery which might cause permanent damage or even death when they are cut. The second is better support for the aftercare and wound treatment. Appropriate aftercare treatments of the wound do not only improve physical well-

being but also enable self-care and encourage the emotional well-being of her participants. The third is promotion of safer injuries. In a heightened state of distress, many people have hurt themselves with whatever at hand. Instead of confiscating their tools of self-injury as is often done in the preventive approach, Inckle suggests the provision of a kit of the necessary supplies for safer injuries and aftercare. Alternative theorisations of self-injury and practical suggestions offered by these scholars have shown how self-cutting might be engaged as an alternative, pleasurable, and ethical practice of self-relation.

This analysis of Putri's narrative has presented another possibility of engaging with/resisting the discourse of sexual desire. While taking up a lesbian subject position, Putri also shows resistance towards the discourse of sexual desire - not by challenging the whole idea of sexual categorisations, but - by cultivating alternative subjectivity which fosters a new form of bodily pleasure (Foucault, 1997). Moving beyond individual-level psychological examination, analysis of Putri's narrative here disrupts dominant meanings around pleasure/pain and sexual/non-sexual dichotomies by engaging in an erotic art of bodily pleasure through the practice of self-cutting.

\section{Conclusion}

This article has discussed how the discourse of sexual desire has been drawn on and contested by young Indonesian participants in the constitution of their sexual subjectivity. Their narratives show various ways to resist scientia sexualis mechanisms operating through the discourse of sexual desire which, in some ways, are reminiscent of Foucault's ars erotica. This means that these participants did not reject the LGBT+ category offered by the discourse of sexual desire, but they took up alternative subject positions from which their sexuality is given meaning in terms of pleasure, relationship, and new possibilities. For instance, alternative subjectivities they cultivated include some possibilities of a new form of sexual relationship (e.g., Bianda's relationship without status) and pleasure (e.g., Heni's reading yaoi or Putri's self-cutting).

The implication of this article for psychology is twofold. Firstly, for psychology as a research field, this article offers an example of how traditionally depoliticised psychological analysis may be repoliticised through a poststructuralist framework that connects individual's sense of sexual self with wider sexual discourses in given society. Secondly, in contrast to traditional approaches of specification and pathologisation of individual problems, psychologists might find benefits in recognising alternative sexual subjectivity as a form of political resistance against oppressive normativities. Instead of clients with psychological problems, individual can be repositioned as activists engaging 
in discursive reworking of sexual politics. Such positioning may open up new possibilities of psychological 'intervention' which are more emancipatory, empowering, and liberating.

It is important to note that a mere imitation of the alternative ways of understanding and practising sexual desire/pleasure exhibited by participants in this article is not encouraged. For instance, I do not suggest anyone simply engage in a 'relationship without status' like Bianda, to read yaoi like Heni, or to cut their skin like Putri as a means of resistance. These examples are intended to illustrate new possibilities of being a sexual subject in relation to the discourse of sexual desire, and not intended to be prescriptive. The erotic art of exploring pleasure discussed here is expected to be approached as a site of possibility rather than a manual. After all, the larger goal of this article is, to quote Foucault (1997), the creation and proliferation of new forms of life, love, relationships, pleasures, and new ways of seeing and being a sexual subject.

\section{Acknowledgments}

This work has been enabled by Indonesian Directorate General of Higher Education through their Overseas Doctoral Scholarship scheme. Author's view in this article does not represent the funder's nor their university's view.

\section{Disclosure statement}

There is no conflict of interest identified in this study.

\section{Funding}

This work was supported by the Direktorat Jenderal Pendidikan Tinggi.

\section{Notes on contributor}

Teguh Wijaya Mulya is a lecturer in psychology at the University of Surabaya, Indonesia. He is a graduate of the University of Surabaya (Bachelor of Psychology); Monash University, Australia (Master of Education); and the University of Auckland, New Zealand (Doctor of Philosophy). He specialises in research in the areas of sexuality, gender, religion, and neoliberalism. His work is inspired by the work of Michel Foucault and post-structuralist feminism.

\section{ORCID}

Teguh Wijaya Mulya (iD http://orcid.org/0000-0002-8899-1157

\section{References}

Barker, M., \& Langdridge, D. (2010). Whatever happened to non-monogamies? Critical reflections on recent research and theory. Sexualities, 13(6), 748-772. https://doi.org/10.1177/1363460710384645

Better, A., \& Simula, B. L. (2015). How and for whom does gender matter? Rethinking the concept of sexual orientation. Sexualities, 18(5-6), 665-680. https://doi.org/10.1177/1363460714561716

Bogaert, A. F. (2006). Toward a conceptual understanding of asexuality. Review of General Psychology, 10(3), 241-250. https://doi.org/10.1037/1089-2680.10.3.241

Braun, V., \& Clarke, V. (2006). Using thematic analysis in psychology. Qualitative Research in Psychology, 3(2), 77-101. https://doi.org/10.1191/1478088706qp063oa

Carastathis, A. (2008). The invisibility of privilege: A critique of intersectional models of identity. The Ethics Forum, 3(2), 23-38. https://doi.org/10.7202/1044594ar

Chandler, A. (2012). Self-injury as embodied emotion work: Managing rationality, emotions and bodies. Sociology, 46(3), 442-457. https://doi.org/10.1177/0038038511422589

Davidson, A. I. (2001). Appendix: Foucault, psychoanalysis, and pleasure. In A. I. Davidson (Ed.), The emergence of sexuality: Historical epistemology and the formation of concepts (pp. 209-215). Harvard University Press.

Diamond, L. M. (2008). Sexual fluidity: Understanding women's love and desire. Harvard University Press. 
Foucault, M. (1978). The history of sexuality, vol. 1: The will to knowledge (R. Hurley, Trans.). Pantheon Books (Original work published 1976).

Foucault, M. (1997). Essential works of Foucault 1954-1984: Ethics, subjectivity and truth (R. Hurley \& a. others, Trans. Vol. 1). The New Press (Original work published 1984).

Gamson, J. (1995). Must identity movements self-destruct? A queer dilemma. Social Problems, 42(3), 390-407. https:// doi.org/10.2307/3096854

Gardner, F. (2013). Self-harm: A psychotherapeutic approach. Routledge.

Inckle, K. (2011). The first cut is the deepest: A harm-reduction approach to self-injury. Social Work in Mental Health, 9(5), 364-378. https://doi.org/10.1080/15332985.2011.575726

Jagose, A. (2010). Counterfeit pleasures: Fake orgasm and queer agency. Textual Practice, 24(3), 517-539. https://doi.org/ 10.1080/09502361003690849

Klesse, C. (2014). Polyamory: Intimate practice, identity or sexual orientation? Sexualities, 17(1-2), 81-99. https://doi.org/ $10.1177 / 1363460713511096$

Klonsky, E. D. (2007). The functions of deliberate self-injury: A review of the evidence. Clinical Psychology Review, 27(2), 226-239. https://doi.org/10.1016/j.cpr.2006.08.002

Kotani, M. (1994). Joseijo muishiki: Tekunogaineshisu, josei SF-ron josetsu. Keiso Shobo.

Nash, J. C. (2013). Practicing love: Black feminism, love-politics, and post-intersectionality. Meridians: Feminism, Race, Transnationalism, 11(2), 1-24. https://doi.org/10.2979/meridians.11.2.1

O'Flaherty, M., \& Fisher, J. (2008). Sexual orientation, gender identity and international human rights law: Contextualising the Yogyakarta Principles. Human Rights Law Review, 8(2), 207-248. https://doi.org/10.1093/hrlr/ ngn009

Smith-Hefner, N. J. (2007). Youth language, gaul sociability, and the new Indonesian middle class. Journal of Linguistic Anthropology, 17(2), 184-203. https://doi.org/10.1525/jlin.2007.17.2.184

Suyemoto, K. L. (1998). The functions of self-mutilation. Clinical Psychology Review, 18(5), 531-554. https://doi.org/10. 1016/S0272-7358(97)00105-0

Tamaki, S. (2007). Otaku sexuality. In C. Bolton, I. C.-R. Jr, \& T. Tatsumi (Eds.), Robot ghosts and wired dreams: Japanese science fiction from origins to anime (pp. 222-249). University of Minnesota Press.

Tweedy, A. E. (2011). Polyamory as a sexual orientation. University of Cincinnati Law Review, 79(4), 1461-1515. https:// ssrn.com/abstract $=1632653$

Weedon, C. (1987). Feminist practice and poststructuralist theory. Blackwell.

Wijaya Mulya, T. (2017). From divine designation to discursive contestation: The constitution of Indonesian Christian young people's sexual subjectivities. New Zealand: (Doctor of Philosophy), University of Auckland.

Wijaya Mulya, T. (2018a). From divine instruction to human invention: the constitution of indonesian christian young people's sexual subjectivities through the dominant discourse of sexual morality. Asian Studies Review, 42(1), 53-68. https://doi.org/10.1080/10357823.2017.1407918

Wijaya Mulya, T. (2018b). Contesting the dominant discourse of child sexual abuse: sexual subjects, agency, and ethics. Sexuality \& Culture, 22(3), 740-757. https://doi.org/10.1007/s12119-018-9506-6

Wijaya Mulya, T. (2019). From vulnerable to responsible youth? indonesian youth resisting the dominant discourse of sexual health. Psychology \& Sexuality, 10(3), 248-260. https://doi.org/10.1080/19419899.2019.1604566

Willig, C. (2013). Introducing qualitative research in psychology. Open University Press. 